\title{
La Crisis de la Modernidad y el 'Debate Post-moderno'
}

\author{
Luis Armando González
}

\section{Introducción: planteamlento del problema}

La modernidad atraviesa por una severa crisis socio — cultural. Se trata, en to fundamental, de una desconfianza radical en la capacidad que pueda tener el ser humano - armado de su razón- para enfrentar los problemas que plantea el predominio exagerado de la "racionalidad instrumental" y/o la "racionalidad eslralégica" (Habermas) sobre las diversas esleras y ámbitos de la realidad personal y social.

A nivel personal nos econtramos con un "hombre unidimensional" (Marcuse), cuya vida se ha reducido a ser mera pieza del engranaje tecnoeconómico. A nivel socio-político nos enconlramos con una tecnificación creciente de la realidad social, cuya expresión más palpable es la marginación de grandes seclores de la población de los diversos ámbitos institucionales en los que se juegan los destinos de la sociedad. Es decir, el mundo moderno atraviesa por un proceso de "despolitización" de la vida social -proceso que está en correlación con una "tecniticación de la política" (Habermas) - y por un proceso de "unidimensionalización" de la vida personal. Ambos dinamismos son el resultado del predominio de la racionalidad instrumental o estratégica.

El individuo -especialmente el del Primer Mundo- se encuentra cada dia más alienado y despersonalizado; hay una pérdida de identidad y de sentido que cada vez se vuelve más aguda. Las respuestas y soluciones "Iradicionales" (sobre todo, las provenientes de la religión) ya no convencen, pero tampoco se avistan nuevas alternalivas. Para los ingentes problemas sociales, económicos y politicos tampoco hay pers- 
pectivas novedosas. Más bien, hay una vuelta hacia posiciones que muchos creian superadas: a nivel socio-oconómico se está operando una vuella hacia un neoliberalismo que hunde sus raices en el liberalismo clásico, especialmente en Adam Smith. A nivel polltico se está volviendo hacia formas de democracia cada vez más elitistas, a través de las cuales se restringe la participación política directa del ciudadano común.

Sin exageración alguna, se puede decir que en el mundo Occidental se eslá produciendo un desplazamiento acelarado hacia la derecha. El "derrumbe" del Este, el fracaso electoral del FSLN en Nicaragua y el eslablecimiento de regimenes neoliberales en América Latina son tres signos importantes -aunque no los únicos-de la derechización creciente de las sociedades occidentales.

Estamos ante una derechización económica que se apoya en una estrategia de desarrollo económico-social de corte neoliberal, y que prelende subordinar el conjunto de las economias nacionales a las economías capitalistas del centro. Volvemos a encontrarnos con un proceso de expansión imperialisla que muchos crelan superado. El capitalismo rapaz ha renacido - la verdad es que siempre estuvo presente y acluante - con nuevos brios y renovada fuerza. Volvemos - ya lo senalamos antes- a Adam Smilh. "Todo antiestatismo actual -nos dice Hinkelammert- comienza con una recuperación de su pensamiento"1. Dicho con otras palabras, volvernos a un capitalismo "que de nuevo puede ser inlerprelado adecuadamente por la visión de mundo de Adam Smith. Eso explica por qué hoy... es nuevamente considerado el clásico principal del pensamiento económico"2.

Esa derechización económica tiene como correlato imprescindible una derechización política que privilegia -por sobre los ideales de pluralismo y de democracia directa - los mecanismos de "democracia formal", a través de los cuales se concentra el poder en las elites polfticas-que cada vez más son élites de derecha- y se reslringe la participación política de los ciudadanos. Nos encontramos con que se imponen ideologías y sistemas políticos que se organizan en torno a una práctica de la democracia fundada en la participación electoral periódica de los ciudadanos, pero que más allá de eso no tiene una Incidencia real en la conliguración de los destinos de la sociedad.

Es decir, cada vez más nos alejamos del ideal $-y$ de las posibilidades reales- de una democracia que sea realmente pluralista y participativa. Resurgen las teorías "elitistas" de la democracia, pero -como hemos indicado- en el marco de una tecnilicación creciente de la política, en el cual los avances y/o retrocesos en la democracia y en la democratización se miden de acuerdo al mayor o menor desarrollo alcanzado en los 
sistemas electorales. En definitiva, se piensa que el problema de la democracia es un problema técnico. Y, si ello es así, habrán de ser los "especialistas" los que lendrán que encontrar la solución adecuada. El ciudadano común - se nos termina diciendo- no tiene por qué intervenir en un ámbilo que no es de su competencia. La creciente "tecnificación" de la política -con la subsiguiente "despolitización" de la sociedad- y la remisión de los problemas socio-económicos al mercado expresan las tendencias históricas fundamentales de nuestro tiempo.

Este proceso de derechización, al parecer, avanza incontenible. La logica y la civilización del capital (I. Ellacuría) se imponen cuasi inexorablemente y no hay forma de conlener su avance. Los proyectos alternativos han entrado en crisis y las soluciones que se dibujan no parecen lener la fuerza suficienle para revertir el proceso. Con el triunfo del capitalismo y el ocaso de los proyectos ulópicos, socialistas y comunistas, parecería que la hipólesis del "fin de la hisloria" (Fukuyama) estaria siendo validada por los hechos. Es decir, parecería que con el triunfo del capitalismo no habría nada nuevo que esperar, ya que to único que se avistaría en el horizonle no sería más que -y sólo- capitalismo. Nos encontraríamos anle el triunlo definitivo del "inlernacionalismo liberal" ( $\mathrm{N}$. Chomski) ${ }^{3}$.

Pero este triunlo de la "lógica y la civilización del capital" y de la "racionalidad estratégica" que la acompańa no se produce sin sobresaltos y conflictos. Los valores, las creencias y las tradiciones resienten la empestida de una racionalidad empobrecida y manipuladora. El hombre mismo no sienle que lo más propio de si consista en ser un homo faber y que su vida se agote en ser una "pieza" del engranaje del sistema de producción. Es decir, el predominio de la "racionalidad insırumental" que no es otra cosa que el mecanismo cientilicista-lecnicisla a través del cual gana concreción y legitimidad la derechización de Occidenlegenera resequedad y desaliento espiritual en el individuo.

El único elemento motivador es el consumo nunca saciado por la abundancia del sistema. Pero el consumo no llena el vacío espiritual ni tampoco dota de un sentido claro y definido la vida del individuo. El sentido de su vida to adquiere el sujeto humano de los valores, las creencias y las Iradiciones en las que se halla inserto. En una palabra, el sentido de la vida se adquiere en el mundo de la cullura: los valores morales, las creencias y las tradiciones propias de la comunidad.

Sin embargo, la "racionalidad instrumental" socava el mundo cultural en cuanto dotador de sentido y de idenlidad. Incluso socava el pilar fundamental de la cultura: la realidad élico-moral. En un universo dominado por la racionalidad científico-técnica —es decir, por el es- ya no 
hay lugar para la razón práctica -es decir, para el deber ser-. En otras palabras, en nuestro mundo Occidental se ha producido una separación radical entre el ens y el bonum (Otto Apel); una separación radical entre el ente -que se impone e invade los diversos ámbilos de la realidad a través de la lógica científico-técnica- y lo bueno, que por carecer de estaluto científico ha de ser abandonado como cuestión humana fundamental.

Nos encontramos ante una prolunda crisis moralespiritual en la que los mismos cimientos del mundo moderno eslán siendo cuestionados. Es decir, nos encontramos ante una crisis que corroe los cimientos mismos de la cullura moderna: la religión, el arte y la filosofia. Estamos ante la crisis de la modernidad. Dar una solución a esta crisis es uno de los grandes desafíos de la modernidad y, como algunos sostienen, de la posimodernidad. Este desatio ha sido asumido por los tres movimientos socio-culturales más importanles de nuestra época: los "neoconservadores" (norteamericanos), los "postmodernos" y la "teoria críti$c a "$.

Estos tres actores intervienen en el llamado "debate postmoderno" dialogando y confrontando críticamente entre si sus tesis lundamenlales-, y su pretensión es realizar un diagnóstico de la crisis moralespiritual que aqueja a la modemidad y ofrecer alternativas para su superación. Este debale está llamado a convertirse en el punlo de referencia obligado si se quiere estar atento a los derroteros que sigue la cullura - europea y norteamericana- de nuestro tiempo. La cultura lalinoamericana habrá de conirontarse tarde o temprano con los horizontes cullurales que se dejan entrever a través del "debale postmoderno". Estas páginas quieren ser una primera aproximación a los actores principales del "debale", asi como lambién a algunas de las cuestiones -interrogantes y respuestas- que pueden suscilar sus tesis y argumenlos desde una perspectiva latinoamericana.

\section{Los actores en el "debale post-moderno": los neoconservadores, los post-modernos y la teorla critica}

\subsection{Los neoconservadores (NC): un movimlento "contra-ilustrado"}

Estamos en un momento en el que los Estados Unidos luchan por imponer en los planos económico, polílico y militar un Nuevo Orden Mundial y en el que algunos -como el editorialista del Telegraph de Londres, Sir Peregrine Worsthorne- proclaman el "retorno del imperialismo occidental". Más aun, nos encontramos con que ese nuevo orden -que no es más que la imposición a nivel mundial de la lógica y la 
civilización del capita- no sólo se impone a través del sometimienlo económico, político y militar de los pueblos, sino que requiere de un componente cultural. Se ha caldo en la cuenta de que la lucha por el establecimiento definitivo de la "civilización Occidenlal y cristiana" ha de librarse en lodos los ámbitos de la vida social, y el ámbito cullural es un espacio privilegiado para esa lucha.

\subsubsection{Los NC ante la "cultura adversarla"}

En Eslados Unidos, un grupo de prestigiosos intelectuales (D. Bell, I. Kristol, M. Novak, P. Berger, Th. Lukmann, S. M. Lipsel, J. R. Neuhaus, ...) han caido en la cuenta acerca del papel fundamental que juega la cultura - especialmente lo cultural-religioso- en la sociedad moderna. Incluso han percibido que en el sistema capilalista no lodo está bien: han caído en la cuenta de que el sistema atraviesa por una "crisis espiritual" y por una pérdida del "correctivo ético" (J. M. Mardones). El mal fundamental del sistema esstriba en la "liquidación de la ética; en la eliminación o desaparición de los valores que sustentan la economía capitalista"4. Esta "liquidación de la ética" es propugnada por corrientes contestarias del sislema que proponen unos valores dislintos a los tradicionales. En electo, la ética propugnada por la "nueva clase del conocimienlo" y los "Nuevos Movimienlos Sociales" (=NMS) (J. M. Mardones) no es una ética que "producirá personas trabajadoras, disciplinadas y amantes del orden. Al conlrario, tendremos individuos nada productivos y bastante hedonistas, justo lo contrario de lo que pide el sistema. Hay, por tanto, que detener esta enfermedad hedonista y recuperar la 'ética de la productividad', el orden y la disciplina"s.

Los que asi diagnostican el mal que aqueja al capitalismo son los llamados neoconservadores (NC) norteamericanos, que constituyen el punto de avanzada de la ofensiva cultural y de la guerra cultural (Kulturkamph (J. M. Mardones) ${ }^{6}$ que el capilalismo libra contra los que, desde el interior del propio sistema, le oponen valores y opciones contrarios a los exigidos para su conservación y reproducción: la "nueva clase del conocimiento", el "modernismo cultural" y el "postmodernismo". Es decir, lo que los aulores NC llaman la "cullura adversaria"?

La "cultura adversaria" eslá constituida por aquellos intelectuales e inslituciones culturales que propagan valores y opciones que minan y erosionan el humus cultural-religioso de la sociedad capitalista. Como ya lo senalamos, la "cultura adversaria" es producida por la "nueva clase del conocimiento", el "modernismo cullural" y el "postmodernismo". 
Los primeros (cientíiticos, urbanistas, Irabajadores sociales, criminólogos, sociólogos...), con sus proclamaciones utópico-socialistas, igualitaristas y de justicia social, "sobrecargan" las tareas del Estado, $\theta$ incluso sus demandas de un Estado de bienestar (Welfare State) les conducen peligrosamente hacia exigencias "colectivistas", y "Totalitaristas", que no reflejan si no un "populismo antielitista" y "resentido". "Se amenaza así la libertad para la exislencia libre del mercado y de la propiedad privada, sin las cuales el sistema político no puede asegurar ni el pluralismo ni las defensa de las libertades fundamentales"s.

Por su parte, el "modemismo cultural" y el "postmodernismo", con su proclamación y defensa del "hedonismo", el "relativisimo", el "experimentalismo del yo", el "hihilismo" y el "individualismo" (que encuentran su campo de expansión y desarrollo en la estética, especialmenle en el arte, la arquileclura y la literatura), no sólo erosionan la cosmovisión cultural (moral-religiosa) de la sociedad y contribuyen, con ello, a la perdida del sentido moral que atraviesa el mundo moderno, sino que promueven un "estilo de vida" contrario al exigido por la dinámica tecnoeconómica del sislema, es decir, auslero, disciplinado, ascélico y, en definitiva, purilano.

La esIrategia cultural NC se deline, hacia al interior del sistema, a partir de su enfrenlamienlo con eslas corrienles socio-culturales. Hay que recuperar la ética puritana para combalir la desmoralización de la sociedad. Es decir, hay que recuperar valores y virtudes perdidos y, desde esos valores y virtudes, dar legilimación al "capitalismo democrático" (M. Novak).

\subsubsection{La reconsthución de la "unidad moral" del sistema}

Los aulores NC hacen un diagnóstico de sistema capitalista: éste alraviesa por una prolunda "crisis espiritual" - cuyo resultado es la "desintegración moral" de la sociedad-que se debe a la pérdida de la tradición cultural-religiosa. Por lo tanto, se trala de reconstituir esa Iradición; es decir, se trala de dolar al sistema de unos valores religiosos (judeo-cristianos) que to legitimen y que sean funcionales y coherentes con los ámbilos tecnoeconómico y político, y que, en consecuencia, contribuyan a recuperar la unidad moral perdida. Hay que reconstituir el "hogar común" (Berger) y la "plaza pública" (Neuhaus) -que padecen de un vaciamiento espiriual y moral- vía la recuperación de la tradición religiosa judeo-cristiana.

"El diagnóslico neoconservador ve amenazados con el relativismo moderno y el postmodemo los fundamentos mismos de la moral, la religión y la sociedad. La imbricación entre eslos tres elementos es tal que soca- 
var uno de ellos conlleva a la calda de los otros. Y al revés, fortalecer el sistema de valores sólo es posible desde una moral civica que propugne la solidaridad, la renuncia a las propias tendencias y egoísmos, fundada en la tradición o humus religioso que lavorezca tal tipo de moral. La tradición judeo-cristiana es una clase de religión apta para efectuar la propuesta de una moral de la solidaridad, de la creatividad y del espiritu de empresa"s.

Estamos ante una "vaciamiento espiritual y moral". Y la siluación es grave ya que el resultado de este vaciamiento moral-espiritual es que "la ética cívica decae $(y)$ los valores que orientan la colectividad de los ciudadanos se vuelven más opacos y conlusos. Las necesidades comunes objetivas se defienden desde los intereses de los grupos que los quieren capilalizar, más que desde la movilización en pro de valores universales favorecedores de todos, especialmente de los peor siluados en la recla de salida social. La plaza pública se vacia"10.

El capitalismo -nos dicen los autores $\mathrm{NC}$ - eslá constituido por tres subsistemas fundamentales: el tecnoeconómico, el político y el cultural. Para que el sistema funcione sin mayores fricciones, enlre los tres subsistemas tiene que haber una coherencia básica, sobre lodo por parte del subsistema cultural".

En la actualidad se ha roto esa coherencia y complementariedad básica debido a las demandas de la "nueva clase" y. sobre todo, debido al "modernisno cultural" y al "postmodernismo" que han entrado en contradiçción con los subistemas tecnoeconómico y político. He aqui el objetivo de la Kulturkampf NC: recomponer culturalmente el sistema capitalista (norteamericano) a partir de una recuperación de la tradición religiosa judeo-cristiana. Esta recomposición encuentra su punlo de apoyo en "las lundaciones o instilutos de investigación ("think tanks") socio-políticos, económicos y culturales que, financiados por multinacionales, son auténlicas fábricas de ideologia destinadas no sólo a polucionar el ambiente intelectual sino... a justificar o legitimar un orden socio-político determinado"12. Al mismo tiempo, se trala de una recomposición que habrá de realizarse via el fortalecimiento de las "instituciones compensadoras" y las "estructuras intermedias" (Berger, Benne, Neuhaus, Novak): "la familia, la Iglesia, las amistades privadas y las asociaciones de libre formación' ${ }^{13}$.

La estrategia cullural NC es clara: "camina por el desarrollo de insliluciones que puedan ayudar a recuperar los valores de la ética puritana: orden, disciplina, capacidad de sacrilicio... Para ello —dirán P. Berger y J. R. Neuhaus - no hay otra salida que la vuelta atrás moral cultural. Es decir, hay que recuperar los valores de los tiempos anteriores propios 
del capitalismo. Pero sin anacronismos. Hay que reforzar las instituciones intermedias compensadoras... Aqui encuentra valor la persona y se impulsa a los individuos a comportamientos solidarios"14.

La propuesta NC es una propuesta contra-ilustrada. Lo que se olrece es una vuelta atrás, es decir, una vuelta hacia valores y tradiciones (morales y religiosas) que acompanaron la expansión del capilalismo norteamericano en sus orígenes. El diagnóstico que se hace de la crisis de la modernidad capilalista $-y$, sobre todo, la idenlificación que se hace de sus principales responsables - lleva al movimiento NC a proponer una terapia bien definida: si el sislema padece una crisis moralespiritual debido a la pérdida de los valores religiosos (judeo-cristianos) que acompanaron su consolidación y desarrollo, hay que recuperar -con una estrategia cullural adecuada- esos valores. Hay que luchar contra los que expanden valores contrarios -provengan eslos de la "nueva clase", la "modernidad cultural" o el "posimodernismo"- porque con ellos lo que se hace es minar los cimientos morales de la sociedad capitalista, sin los cuales ésta pierde cohesión y se destintegra.

\subsection{El post-modernlsmo: un movimlento "post-llustrado"}

El post-modernismo es uno de los movimientos socio-culturales que más ha impaclado el quehacer inteleclual de las últimas décadas. Ya no se trata - como muchos pensaron inicialmente- de una moda pasajera. No cabe duda de que sus tesis son disculibles y quizás hasta inaceptables, pero la confrontación con ellos es ineludible. Los posi-modemos lienen una propuesta en torno a los problemas de la modernidad y sobre la forma de enfrentarlos. Dicha propuesta a ganado concreción tanto en el ámbito estético -con los estetas italianos (Vattimo, Venluri, Casloriadis...) - así como también en el ámbilo filosófico -con los postestructuralistas franceses (Braudillard, Faucault, Lyotard...)-

Siendo rigurosos, tenemos que decir que la posl-modernidad, más que un movimiento, es una sensibilidad, es decir, una experiencia que ha sido forjada al calor de las crisis económicas, políticas y culturas que han sacudido a la modernidad burguesa desde mediados del siglo $X X^{15}$. Cuando se habla de post-modemidad, pues, hay que pensar antes que nada en un "clima cullural" (J. M. Mardones) que se caracteriza por una actilud de rechazo y de crítica a los valores culturales, económicos, politicos y sociales de sociedad burguesa liberal' ${ }^{16}$.

\subsubsection{La post-modernidad y la crisis de la modernldad}

Hemos visto que los autores NC acusan al post-modernismo de ser el 
responsable de la crisis cultural-espiritual que atraviesa la modernidad. Cuando los NC sostienen que los postmodernos propagan valores hedonistas, relativistas e individualistas no están haciendo senalamienlos falsos. Sin embargo, ver en esas expresiones socio-culturales una de las causas de la crisis de la modemidad capitalista, eso sl que es disculible. Los NC perciben de esa forma el problema porque han desplazado su análisis de la realidad social -de lo tecnoeconómico y político- hacia lo cultural, haciendo de éste el ámbilo fundamental.

Pero no es tan fácil sostener que los problemas fundamentales del mundo moderno tengan su raiz del subsistema cultural. No se puede pasar desapercibido que muchos de las crisis y conflictos de nuestro tiempo se originan en los ámbilos tecnoeconómico y político. La dinámica tecnoeconómica (y política) capitalisla sigue generando crisis, recesión y marginación. La explotación de la mano de obra y los recursos nalurales del Tercer Mundo siguen estando a la orden del dia. Incluso la depredación del planeta a alcanzado niveles tales que es la misma supervivencia de la humanidad la que está en juego...

Desplazar lo lecnoeconómico y político como lo fundamental y centrar la atención en lo cultural es caer en una simpliticación bastante injustificada. Sólo a'partir de esa simplificación es que se puede buscar las causas de la crisis de la sociedad capilalisla en el ámbilo cullural e incluso hacer responsable de esa siluación de crisis a un movimiento socio-cullural. Pero si se asume otra perspectiva la visión del problema puede cambiar. Para el caso, si se asume que la crisis de la modernidad capilalista no es fundamentalmente cultural - sino socio-económica y política- y que, más bien, lo cultural es un ámbilo en el que la misma se expresa. Si ello es asi, habrá de verse a los postmodernos — incluso a los mismos NC- como un movimiento socio-cultural no responsable o causante de la crisis, sino como un movimiento que es expresión de ella, y que - más aún- quiere ofrecer -al igual que los $\mathrm{NC}$ - un diagnóslico de la situación y una propuesta para enfrentarla.

En nuestra opinión, pues, el movimiento post-modemo liene lanta legitimidad -en cuanto movimiento socio-cultural- como el movimiento neoconservador. De insistir los NC en sus acusaciones, los post-modernos podrian perfeclamente devolverles el reproche de ser ellos los responsables de la crisis de la modernidad, por los valores y el estilo de vida que propagan. Aunque obviamenle también los post-modernos se equivocarian: si las causas lundamentales de la crisis no son cullurales no tienen porque buscarse en el ámbito cullural ni, mucho menos, responsabilizar de la misma a un movimiento socio-cultural determinado. 


\subsubsection{La "post-llustración" de los post-modernos}

Los post-modernos son sensibles a la crisis de la modernidad, y en su diagnóstico de la siluación y en su propuesla de solución quieren ir más allá de la ilustración. "Postmodemo será comprender según la paradoja del fuluro (post) anlerior (modo)" (Lyotard). El "momento postmoderno" (Wellmer) es un momento de "unmaking" (deshacimiento) (I. Hassan).

El post-modemismo es un "momento antinómico que asume un vasto proceso de deshacimienlo en la mente occidental, to que Michel Foucault hubiera llamado una episteme posmoderna. Y habla de unmaking (deshacimiento) aunque estén en boga otros lérminos, por ejemplo: deconstrucción, decentración, desaparición, diseminación, desmilificación, discontinuidad, diferencia, dispersión, elc. Tales lérminos expresan un rechazo ontológico del sujeto Iradicional pleno, del cogito de la filosofia occidental. Expresan también una obsesión epistemológica por los fragmenlos o las fracturas y un correspondiente compromiso ideológico por las minorias en política, sexo y lenguaje. Pensar bien, sentir bien, acluar bien, de acuerdo con esla episteme del deshacimiento, es rechazar las tiranias de las totalidades; la lotalización en cualquier empresa humana es potencialmente tolalitaria"17.

Los post-modernos son radicales en sus lesis. Quieren ir más allá de los mismos "maeslros de la sospecha" (Ricoeur). Les parece que la modernidad misma es la que está en crisis, y que la causa de ello radica en la crisis de la razón ilusirada que le sirve de fundamento. Con la crisis de la modernidad estamos ante la crisis de la llustración. Los proyectos utópico-emancipadores ilustrados se vienen abajo; la razón como garanlía absoluta de la lelicidad y la libertad humanas pierde su estaluto emancipador. Y si hay que buscar un responsable de la crisis, ese responsable es la misma racionalidad ilustrada, cuyas lundamentos manipuladores y dominadores -que se esconden bajo un discurso aparentemenle emancipador y liberador- lerminan imponiéndose al hombre, esclavizándole y oprimiéndole.

La razón ilustrada es, en esencia, manipuladora y dominadora. La ciencia y la técnica han "Yriunlado" en el mundo moderno (Vattimmo) y han expandido el poder manipulador de la razón a todos los ámbitos de la vida humana. Es esa "voluntad de poder" (Nietzche) la que se esconde - $e$ incluso se intenta justificar y legitimar- en los grandes melarrelatos (filosóficos y metalísicos) que ha producido la civilización occidenlal a lo largo de su historia. Hay que luchar contra la razón totalizante y su sujeto (Wellmer); hay que enIrenlar el "terrorismo de la teoría", de la "representación", del "signo" y de la "idea de verdad"(Lyolard) ${ }^{18}$. 
Romper con los grandes metarrelatos (producidos por la "razón tolalizanle") signitica decir "un adiós a las grandes narraciones (la de la emancipación de la humanidad o la del devenir de la idea), y al fundamentalismo de las grandes legilimaciones, asl $\infty$ mo a la ideologla sustitutoria, pero lambién lotalizante, que representa la leorla de sistemas; y por otra parte, como un rechazo de las formas tuturistas de pensamiento tolalizante, complementarias de las amteriores: de las uloplas de la unidad o de la reconciliación o de la armonia universal" ${ }^{\prime \prime}$. Se trata de romper con las grandes "metanarrativas" y con las "legitimaciones universalistas", asi como de entrentarse al principio de "realizalividad (performantivity) y de buscar una "legitimación a través de la 'invención' del olro"(Lyotard) ${ }^{20}$.

La ruplura con los melarrelatos y las metanarrativas liene como finalidad última lograr una "deslegitimación de la modernidad europea" (Lyolard), "deslegitimación de la cual la filosotía de Nietzsche representa un documento temprano y central"z1.

Aulores como Jean Braudillard anuncian sin reservas la "muerte de la modernidad" (Wellmer): "El futuro ha llegado, todo ha llegado, todo está ya aqul... a mi entender, ni tenemos que esperar la realización de una utopia revolucionaria ni tampoco un acontecimiento alómico explosivo. La fuerza explosiva ha entrado ya en las cosas, ya no hay que esperar nada más... lo peor, el sonado aconlecimiento tinal sobre el que loda utopía construia, el esfuerzo metatísico de la historia, etc., el punto tinal es algo que ya queda atrás de nosotros"z2. Para Braudillard, con la postmodernidad nos encontrariamos en el "fin de la historia" (Fukuyama); es decir, "la posmodernidad seria ya una realidad histórico-ahistórica consumada, habría ocurrido ya la muerte de la modemidad. Pero la sociedad posmoderna sería un inesperado híbrido de las visiones de la teoría de los sistemas y de los suefios de Ludwig Klages: el renacimiento del reino arcaico de las imágenes a partir del espiritu de la electrónica modernama.

\subsubsection{La "fragmenlaclón" de la modernldad y la crisls del proyecto llustrado}

La modernidad se ha resquebrajado - nos dicen los post-modernosdesde sus propios fundamenlos: el sujeto y la razón. Aqui nuestros autores asumen una tesis ya delendida por Max Weber: la lesis de la fragmentación de las diversas esferas de la realidad social y del conocimiento en el mundo moderno. A nivel psicológico, se ha hecho patente la "inexistencia de un sujelo aulónomo", asi como la "irracionalidad ráctica de su aparente razón"24. "Se trata del descubrimiento del otro de la razón 
dentro del sujeto y de su razón: como criaturas corporales, como máquinas deseantes o también... como voluntad de poder, los individuos no saben qué desean ni que hacen; su razón es simplemenle expresión de relaciones psíquicas y sociales de poder"s. El sujeto humano - en el fondo- no es más que "el escenario de una cadena de conllictos, más que el autor de un drama 0 el autor de una historia"zo, cuya "unidad" $y$ "autotransparencia" en cuanto "si mismo" resulta ser una "ficción": "el sujelo lilosólico con su capacidad de autodeterminación y de logon didonai queda desenmascarado como un virtuoso de la racionalización al servicio de fuerzas ajenas al ego, (que) no es más que un débil mediador entre las demandas del id y las amenazas del superego"27.

Pero el sujelo no sólo ha perdido su unidad subjetiva a nivel psicológico. También a nivel lingüistico se pone en cuestión la unidad del sujelo defendida por la teoría racionalista del lenguaje. El exponente máximo de esta "crítica de la teoría que entiende el significado según el modelo del nombre" (Wellmer) es L. Wittgensiein, cuyo planteamiento "destruye al sujelo como autor y juez linal de sus intenciones de significado"ze.

Si queremos conocer el significado de las palabras o de un determinado lenguaje - nos ensefia Wittgenslein - no debemos remitirnos al sujeto, sino que debemos atender -y ser participes-del "juego del lenguaje" correspondiente; es decir, lenemos remitirnos a la "práctica intersubjetiva" que realiza la comunidad de hablantes-oyentes. "Los juegos del lenguaje no son juegos, sino lormas de vida. Son conjuntos de actividades lingüísticas y no lingüisticas, instiluciones, prácticas y signilicados encarnados en ellas"zo. Y los "juegos del lenguaje" tienen sus reglas especílicas, cuya vigencia "no se funda en otra cosa sino en la práctica de su propia aplicación a una clase de casos abierta en principio, de forma que la relación de significante es una encamación de esta práctica y no una relación entre dos relata en cierto modo ya dados con independencia el uno del otro"30.

El sujelo -como podemos ver- pierde su predominancia y centralidad. Anles que el sujeto y su individualidad solipsista está la comunidad inlersubjeliva que se halla inserla en "juegos de lenguaje" determinados. El sujeto no se agota en su racionalidad subjetiva. La crítica de Wittgenstein destruye el "subjelivismo lingüístico". "Al igual que la crítica psicológica, la crítica que la filosofía del lenguaje hace al sujeto conduce al descubrimiento del otro de la razón dentro del otro. En cada uno de los casos se trata de un dislinto "otro" de la razón. Mientras que la destrucción psicológica del sujeto implica el descubrimiento de las fuerzas fuerzas libidinales (y del poder social) dentro de la razón, la destrucción del subjetivismo en lérminos de filosolía del lenguaje condu- 
ce al descubrimienlo de un cuasi-factum que precede a loda inlencionalidad y subjetividad: sistemas de significados lingüisticos, formas de vida, un mundo que en cierlo modo ha sido lingüislicamente develado"31.

La drílica de Wittgenstein nos hace caer en la cuenta de que el sujeto no es lo fundamental, sino que lo fundamental es un "mundo alumbrado lingüisticamente" (Wellmer). "No se trala aqui de un mundo sin sujelo, sin 'sí mismo', se trala más bien de un mundo en que los seres humanos pueden ser ellos mismos o no serlo de diferentes modos"32.

Con la quiebra de la modernidad también ha entrado en crisis el proyeclo enmancipador de la ilustración, debido al predominio creciente de la "razón instrumental" (Habermas) y la "lógica de la idenlidad" (Wellmer) en la que aquélla se fundamenta. Y el problema de fondo radica en que la razón ilustrada es una "razón objetivante" y "creadora de sistemas" (lotalizante) (Wellmer). Es decir, la razón ilustrada es una razón manipuladora y dominadora. Toda la modernidad —en sus diversos "procesos de racionalización" económicos, politicos, sociales, culturales- está penetrada "de esta razón objetivante, unilicante, controladora y manipuladora" ${ }^{33}$, cuyas consecuencias más graves son la "burocralización" y "cientifización" de la vida social (Weber).

Las propuestas emancipadoras ilustradas propias de la modernidad apuestan "por el progreso de la humanidad hacia la razón"34. "La ilustración - nos dice Wellmer- esperaba de la razón algo distinto y mejor que el mero progreso lécnico, económico y administrativo: la abolición de la dominación y del autoengaño a través de la abolición de la ignorancia y de la pobreza"35.

Sin embargo, la consecuencia práclica de esa propuesta emancipadora no fue más que un "tolalitarismo de la razón, cuya racionalidad quedó desenmascarada en el lerror estalinista" (Wellmer). Es decir, la ilustración terminó generando aquello que se proponia abolir: somelimiento y opresión. Pero -nos dicen los post-modernos- el sometimiento y la opresión no son ajenos al proyecto ilustrado. A la racionalidad ilustrada le pertenece -como un momento constitulivo suyo- el ansia de poder y de dominación. El mal de la modernidad es generado por ella misma. Quiere emancipar al hombre y termina -por sus propios dinamismos manipuladores- someliéndole. Ello no puede ser de olra forma, ya que la razón ilustrada es en fondo una "razón instrumental" y una "razón objelivante". 
Es esa razón manipuladora y objetivante la que es legitimada por el pensamiento de la identidad que se expresa en los metarrelatos y las metanarralivas. "En el carácter cerrado de los sistemas filosóficos y en la búsqueda de fundamentaciones últimas que caracteriza a la filosofia se expresa el deseo de seguridad y dominación que caracteriza al pensamiento identificante. Un deseo que se aproxima al delirio. En los sistemas de legitimación de la edad moderna - desde la teoría del conocimiento a la filosofía moral y política- se oculta un resto de delirio mítico traducido en forma de racionalidad discursiva" ${ }^{\prime 30}$.

Al enirar en crisis el proyecto ilustrado -por la colonización que de los diversos ámbitos de la realidad social hace la "razón instrumenlal"-. también entran en crisis las grandes legilimaciones teoricas que le han servido de sustenlo. En definitiva, el proyecto emancipador ilustrado se ha resquebrajado ya que la racionalidad en la cual se fundamenta es una racionalidad "identificante, sistematizante y unificante, en una palabra: una razón totalizante"37. Esta "razón totalizante" no puede conducir a la emancipación socio-política y económica: "la práctica política se convierte en una técnica para la conservación del poder, de la organización y de la manipulación. La democracia se convierte en una forma eficiente de la organización de la dominación política ${ }^{330}$.

\subsubsection{La alternativa post-moderna}

Los post-modernos hacen suya la experiencia de fragmentación del mundo moderno y proponen un modo de encarar la situación que se vive. Hay que asumir hasla sus últimas consecuencias la crisis del proyecto ilustrado, aceptando "sin noslalgias el pluralismo inconmesurable de los juegos del lenguaje (Witigenstein) o de las esferas de valor (Weber). La única opción racional que cabe en esta situación es la paralogia" "Más aún, en opinión de Lyotard, "renunciar sin desencanlo a los meladiscursos legitimadores es la característica fundamental que separa el saber moderno del posimoderno"40.

Siguiendo a J. M. Mardones, podemos decir que los post-modernos tienen una propuesta de "resistencia" al proyecto de la modernidad. Esta propuesla adquiere pertiles propios en la medida que se examinan los rasgos más sobresalientes del pensamiento post-moderno. El pensamiento post-moderno se caracteriza por ser un pensamiento de la fruición; un pensamiento de la contaminación y un pensamiento del mundo de la técnica moderna". 
a) Como un "pensamiento de la fruición", el pensamiento post-moderno "quiere tener valor en sl mismo. No quiere ser utilizado para transformar la realidad, sino que pretende vivir la realidad en sí misma". Se trata de una "actitud vital" 0 de un "estilo de vida" (J. M. Mardones) que consiste en un "rechazo radical de la insinumentalización de la razón (Horkheimer) y de la misma vida, y afirmación de lo vivido en cada momento 'sin función de preparar otra cosa"mas. Hay que vivir el presente sin intentar "escapar" de él, es decir, no hay que buscar más allá de lo dado "la auténtica realidad, en el manana justo, solidario y libre que haremos. Estamos ante un "esteticismo presentista" (J. M. Mardones). Detrás del fulurismo emancipador se esconden, dicen los postmodernos, la vuelta repetitiva de la funcionalización del pensamiento, de la coerción y el disciplinamiento de la voluntad, y el eterno retorno a los valores de la modernidad"at.

b) Como un "pensamiento de la contaminación", el pensamiento postmoderno estarla abierto "radicalmente a la mulliplicidad de los juegos del lenguaje (Lyotard) que la cultura y el saber actual nos ofrece desde la ciencia, la técnica, el arte o los 'mass-media'. Nos encontrariamos con ese 'vagabundeo incierto' que impone una siluación en la que no hay principios ni criterios tijos, determinados, fundados de una vez por lo-

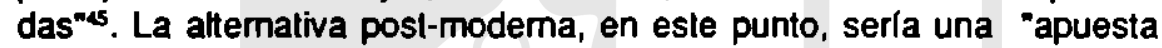
por la apertura, por la dislocación de lo hasta ahora coherentente; propone romper "los mélodos consagrados y ofrece la discontinuidad, la búsqueda del discenso y la ineslabilidad como to verdaderamente humanond7.

c) Finalmente, como un "pensamiento del mundo de la técnica moderna", el pensamiento post-moderno es el pensamiento que se corresponde a una situación de "relativa seguridad" -individual y sociał- alcanzada en "virtud de la organización social y el desarrollo técnico" (Vattimo) ${ }^{48}$. Es decir, nuestros autores hacen suya la tesis de Haidegger según la cual en la modernidad la melafísica alcanza su desarrollo más complelo, siendo su producto más acabado la técnica, que es "el produclo acabado del pensamiento fundado que asegura la razón y del cual la razón se asegura... El triunto de la técnica es el triunío de la melafisica; por eso en la esencia de la técnica se revelan los rasgos propios de la metalísica y del humanismo occidental" ${ }^{40}$. Pero -como ya lo hemos sefialado- los aulores post-modernos están convencidos de que en la actualidad la metaf/sica está siendo superada; por consiguiente, también está siendo superada la supremacía de la "racionalidad estratégica" o técnico-científica.

El sujeto -nos vienen a decir los post-modernos- debe insertarse 
en esa dinámica en la que la propia modernidad se está autosuperando: "el sujeto... debe abandonarse, ceder en su pretensión objetivadora y dominadora, entregarse a la vivencia del momento, perderse en lo terreno"so.

En resumen, los autores post-modernos tienen una visión bastanle delinida acerca del mal que aqueja a la modernidad. El proyecto de la modernidad está edilicado sobre una racionalidad manipuladora y dominadora, que es legitimada en los grandes metarrelatos y metanarrativas. Se trala de oponer resistencia a esa racionalidad y a sus legitimaciones teóricas fundamentadoras. La misma dinámica de la modernidad ha llevado a una crisis de sus supuestos fundamentales: el sujelo y la razón. Ambos se han fragmenlado. Esa fragmentación se hace senlir en las esteras psicológica (Freud), socio-histórica (Weber, Marx) y del lenguaje (Wittgenslein), y el elemento que la posibilita -que es constilulivo a la razón ilustrada - es la "voluntad de poder" (Nielzche). Hay que vivir ese presente Iragmentario, llevándolo hasla sus últimas consecuencias, sin "nostalgias" y sin "desencanto" $y$, además, sin pretender recuperar la unidad perdida y, mucho menos, los grandes metadiscursos legilimantes. Hay que dejarse arrastrar por el fragmento, viviéndolo de un modo "sensible-estético", único que puede garantizar la auténtica realización humana, en libertad, sin manipulaciones, alincada en "consensos locales" (J. M. Mardones) y sin el peligro de verse atraida por proclamas emancipadoras de ningún tipo.

\subsection{La teoria crítlca (TC): la "autranscendencia de la razón llustrada"}

La TC interviene en el debate post-moderno con unas preocupaciones y unas propuestas bien concretas. Es un movimiento socio-cultural al que se le tiene que preslar atención no sólo por la larga tradición inteleclual que lo respalda, sino también por los acentos propios de su diagnóstico y por la crilicidad que acompana a sus planteamientos y allernalivas.

Como movimiento socio-cultural, la TC se inscribe en esa inslitución de la tradición cultural alemana más imporlante del siglo XX: la Escuela de Frankfurf ${ }^{1}$, entre cuyos miembros más deslacados encontramos a pensadores de la talla de M. Horkheimer, Th. W. Adorno, W, Benjamin, H. Marcuse, E. Fromm...

La TC actualiza -sobre lodo de la mano de aulores tales como $\mathrm{C}$. Olle, A. Wellmer, J. Habermas, y K.O. Apel- la inspiración y los intereses emancipadores de los fundadores de la Escuela: Horkheimer, Adorno y Benjamin. La TC apuesla por la emancipación de la humanidad; más aún, es un movimiento que quiere incidir eleclivamente en dicho 
proceso. Sus mentores apuestan por la razón ilustrada y las elaboraciones leóricas que buscan algún tipo de fundamemación úttima en la realidad. "Sin ingenuidades ni falsas ilusiones, quieren proseguir el programa ilustrado que pretende hacer de la razón y del sujeto elementos primordiales de la construcción de una sociedad justa racional y humanam52.

De momemto, van a ser estos dos rasgos los que van separar a la TC tanto del neoconservadurismo como del posl-modernismo. Por cotraposición a los NC -que proponen una vuelta a las fuentes de la tradición religiosa (judeo-cristiana), to cual hace de su planteamiento un planteamiento "contra-ilustrado"-, los TC (=teóricos críticos) van insertar su quehacer en una propuesta emancipadora racional-ilustrada, es decir, no tradicional-religiosa y orientada hacia la transformación social. Los TC también mantienen posluras que los alejan de los post-modemos en un punto especilico: el problema de las lundamentaciones filosóficas. Los post-modernos -ya lo hemos visto- son reacios a aceptar cualquier elaboración de tipo melafísico, mientras que los TC si aceptan, aunque con matices y algunas reservas, las elaboraciones metafísicas.

En concreto, Otto Apel y Habermas ${ }^{53}$ se remilen expresamente a la filosofía de Kant para soslener y argumentar sus tesis fundamentales. Asumen el horizonte de la filosolía trascendental de Kant y, desde el mismo, elaboran su diagnóstico de la crisis de la modernidad y proponen una alternativa para enirentarla. Quieren que la razón ilustrada se aulotrascienda, superando los límiles que le impone la "razón instrumental". Sólo asumiendo la perspectiva kantiana se puede alcanzar la autotrascencia de la razón ilustrada (J. M. Mardones). Y sólo desde esla aulolrascendencia se pueden enlrentar adecuadamente los problemas que tiene ante si la humanidad actual. "En términos de ideología político-social, prosiguen crilicamenle la tradición socialista, marxista, mediante una 'democracia radical' que no puede alcanzarse sin reapropiarse el 'universalismo político-moral de la llustración, las ideas de autodelerminación individual y colectiva, de razón e historia, de una nueva forma'. Se silúan... en el nuevo paradigma de la filosofía posterior al 'linguistic lurn' y participan de la crítica a la 'episteme' de la representación"st.

\subsubsection{La crisis de la modernidad y el predominio de la raclonalldad instrumental o estratéglca}

La TC es particularmenle sensible a la "colonización" que ejerce en los diversos ámbilos de la realidad social la "racionalidad insinumental". Eslos autores van a prestar especial alención -en su diagnóslico de la crisis de la modernidad- a la incidencia de esa "racionalidad ins- 
trumental" -que rige en el ámbito tecnoeconómico-sobre el ámbito politico. Harán notar, como uno de los electos más nefastos de aquella colonización, la creciente "lecniticación de la política" - con la consiguiente "despolitización de la sociedad"- que marca cuasi inexorablemente el destino de las sociedades occidentales.

Los aulores de esta corriente son conscientes de la crisis que atraviesa a la modernidad. Muchos de los males diagnosticados por los NC y los post-modernos son aceptados por la TC. Estos üllimos aceptan que hay una crisis en los valores ético-morales y aceptan también que hay una pluralidad de visiones de mundo (de juegos de lenguaje) que remiten más hacia los "consensos locales" que hacia las grandes cosmovisiones y metarrelatos.

Pero nuestros autores tienen sus reservas respeclo de los diagnósticos NC y post-moderno. Los post-modemos sostienen que la crisis hunde sus raices en la misma razón ilustrada que sirve de soporte al mundo moderno. Es la razón ilustrada -en sus diversas manilestaciones: estélicas, filosólicas y científicas - la que ha dado pie a las aberraciones de la humanidad occidental. La terapia que se impone no es otra que la de la ruptura de los supuestos (psicológicos, lingüísticos y antropológicos) de la ilustración.

Los TC no están de acuerdo con la radicalidad de este diagnóstico post-moderno. Si que la razón ilustrada ha incidido en la conliguración del mundo moderno (occidental), de su técnica, su ciencia y su filosofia. Pero el mal de occidente no radica en eslo. El problema de la modemidad es que progresivamente una de las dimensiones de la razón ilustrada - la razón técnica - ha ido convirtiéndose en el paradigma de las otras dimensiones de la razón. Más aún, la razón técnica -la razón instrumental o estralégica - ha ido colonizando a los otros ámbitos de la racionalidad humana, convirtiéndose en la razón por antonomasia. Todos los procesos de "tecnilicación" de la vida social -la política, la educación, la cullura, etc.- son expresión de esla colonización y predominio de la razón insirumental sobre las olras esieras de la razón. Habermas ha percibido con gran claridad esle problema. Para él "los descontentos de la modernidad se originan, no en la racionalización como tal, sino en el fracaso para desarrollar e institucionalizar de una manera equilibrada lodas las dimensiones de la razón inauguradas por la comprensión del mundo moderno"s5.

La racionalidad que se ha impuesto es una racionalidad "sistémica" (Habermas) cuya lógica intrinseca es la manipulación y el dominio de to otro y del olro. "La lógica 'oculta' de esla forma de racionalización es una lógica de dominio y represión que va en aumento. El dominio de la 
naturaleza se convierte en un dominio de los seres humanos sobre otros seres humanos, y en úllimo lugar en una pesadilla de autodominionsa.

La solución no consiste en renegar de la razón ilustrada, sino en reasumir aquellas dimensiones suyas que han sido relegadas por el predominio de la racionalidad instrumental. Los proyectos emancipadores en sl mismos no son nocivos para la humanidad, sino en cuanto que están penetrados de la "voluntad de poder" (Nietzche) propia de la razón manipuladora y dominadora. Hay que "limpiar" a la razón emancipadora (razón critica) del sesgo manipulador de la razón dominadora, que ha de ser recluida en el contexto específico suyo de dominación y control de la naturaleza. Es decir, hay que vincular las dimensiones de la razón a los intereses específicos que persigue la sociedad humana. Hay que vincular conocimiento e interés (Habermas). El conocimiento que se construye (ya sea cientifico-natural, históricosociológico o filosótico-teológico) ha de estar estrechamente relacionado con los intereses (de dominio, relación o emancipación) de la sociedad ${ }^{57}$.

La modernidad ha hecho del conocimiento cientílico-natural -que responde al interés de dominio sobre la naluraleza - el conocimiento por exelencia, relegando a un segundo plano los conocimienlos que responden a los intereses de relación (social) y de emancipación, 0,10 que es peor, calcando éslos según el modelo de aquél. La consecuencia de todo esto es que las prácticas de relación social y las prácticas emancipadoras han sido contaminadas con un conocimiento y unos intereses que le son ajenos. Liberar al conocimiento socio-histórico y al conocimiento emancipador - asi como a las prácticas que les corresponden- de un conocimiento y unos intereses manipuladores dominadores: he aquí el camino de solución propuesto por la TC en respuesla a los post-modernos.

En otras palabras, para la TC hay "posibilidades alternativas" de racionalidad y racionalización. "Lo que ha sucedido en la sociedad modema (...) es un proceso seleclivo de racionalización -donde la racionalización deliberado-racional prevalece, se inmiscuye, y deforma el mundo vital de la vida colidiananse. Hay que fomentar un tipo distinto de racionalidad, no manipuladora y dominadora. Es decir, hay que "fomentar la racionalidad comunicativa del mundo vital y lograr un equilibrio adecuado entre las exigencias legílimas de la racionalización sistemática y la racionalización comunicativa del mundo vital"59.

En la racionalización comunicaliva radican "los fundamentos racionales de una esperanza social" (R. J. Berstein). Como nos dice Berstein a proposito del planteamienlo de Habermas: "El es una voz fuerte y poderosa que nos recuerda que la necesidad práctica para incorporar y nutrir 
la racionalidad comunicaliva en nuestras prácticas sociales colidianas tiene un 'obstinado poder transcendente', porque se renueva con cada acto de comprensión libre, con cada momenlo de convivencia en solidaridad, de individuación de éxilo, y de emancipación salvadora"son.

Los NC piensan que la crisis de la modernidad es espiritual. Ahora bien, la falla de los NC radica en la explicación de las causas de la crisis. Estas causas hay que buscarlas - nos dice la TC - no en el ámbito cultural, sino en el ámbilo tecnoeconómico y derivadamente en el político y el cullural.

Es cierto -dicen los TC- que el mundo moderno está constiluido por tres ámbitos fundamentales: el lecnoeconómico, el cultural y el político. En esto han acertado los NC. Pero en lo que han fallado es en la elección de la instancia a la que asignan el peso fundamental en la génesis de la crisis.

Para ellos la instancia lundarnenlal de la sociedad es el orden cultural. Para la TC el orden fundamental es el lecnoeconómico. Asumen la "autonomia relativa" de cada uno de ellos, pero no caen en el simplismo de ignorar el influjo de lo lecnoeconómico sobre lo político y cultural. No son ingenuos a la hora de ponderar el peso fundamental que tiene dicho orden en la configuración de las sociedades capilalistas modernas. Por tanto, siguiendo a la TC, habría que buscar los males de la modernidad capitalista -y la terapia para los mismos- en el orden tecnoeconómico.

Habermas, en concrelo, "invertirá la interpretación y dirá que quien tiraniza al sistema social moderno no es la cultura, sino los sistemas tecno-económico y burocrálico. La cultura, es decir, las matrices de sentido y significado para el hombre y la sociedad son invadidas por los valores y la racionalidad predominantes, que provienen de los ámbitos económico-técnico y burocrático-administrativo. Nos encontramos asi con un predominio colonizador, violento, de lo funcional, lo pragmálico, lo utilitario, lo rentable, lo procedimental, lo legal, que invade terremos que no son ya los de la economia y la burocracia. Penetran en el ámbito de las relaciones personales, de la pareja, la sexualidad, la educación, o las más sociales del estilo de vida y los objetivos y necesidades de una colectividad"s1.

Nos encontramos con un predominio creciente de la lógica tecnoeconómica. Uno de los males fundamentales que produce esa lógica es el consumismo desenfrenado que se ha apoderado del hombre de la sociedad moderna occidental. "La causa hay que buscarla en las innovaciones lecnológicas, que llevan la electricidad y los aparalos ligados a ella al hogar... La producción masiva de objetos exige líneas de 
montaje que abaraten la producción en serie de automóviles o aspiradoras. Pero requiere también desarrollar el apelito de sus compradores hasla estabilizar grandes colectivos de clientes. Esla función la va a cumplir la publicidad"62.

Esle consumismo desenirenado ha producido "patologías" profundas en la sociedad occidental moderna (J. M. Mardones): "el cambio introducido por el consumo masivo no sólo incide sobre el mundo económico, sino sobre el cultural y, por tanto, alcanza a la configuración de un estilo de hombre, de vida y de relaciones sociales" Se genera un "estilo de vida" caracterizado por la "posesión" y el "goce", es decir, por el "deseo de tener" (J. M. Mardones). Este deseo "genera una actitud cognoscitiva. La realidad es vista desde un punto de vista del interés posesivo; de ahí que, fundamentalmente, se vean 'cosas', 'objetos', para conseguir, manipular, usar, disfrutar. Es una visión cosista y cosificadora de la realidad. Todo queda referido al mundo de utilidades del sujeto. Este se constituye en el centro, a cuyos intereses, deseos o caprichos se debe supeditar todo"6s.

La primera consecuencia grave de esa dinámica consumista es que "se expanden las relaciones interesadas, estralégicas, orientadas a la consecución de los intereses propios" 6 . Sin embargo, "en el límite, el consumismo termina entronizándose como absoluto... Un Idolo competidor del Dios verdadero, Moloch de las sociedades nortallánlicas, en cuyos allares se inmolan los sacrilicios de incontables victimas humanas" ${ }^{\text {"Bo }}$.

$Y$ aqui volvemos de nuevo a la crítica de la racionalidad instrumental elaborada por la TC. En efeclo, el orden lecnoeconómico inslaurado en la modernidad capilalista es un orden "manipulador" de la realidad natural, que, llevado hasta sus últimas consecuencias en la actualidad, está "depredando" el ecosistema hasla límiles crílicos, en los que la misma vida humana sobre el planela corre el riesgo de verse imposibilitada. Pero no sólo se trata de una depredación del ecosistema. Se trata también de una colonización que ejerce ese patrón manipulador (instrumental y estratégico) sobre la tolalidad de las relaciones sociales. En esta lógica, lodo está sujeto al "control" y al "cálculo": desde la políica hasta la educación de los hijos.

Este imperio de un estilo de vida fundado en una racionalidad de tipo instrumental es -en el diagnóstico TC- una de las causas fundamentales de la crisis de la modernidad. Por consiguiente, la terapia propuesta por estos aulores apunta hacia el mismo ámbito desde donde esa racionalidad se ha geslado y se ha expandido hacia el conjunlo de la sociedad: el ámbito tecnoeconómico. No se trata, pues, de una cuestión meramente cultural, como piensan los NC y, en cierto modo, lambién los 
posl-modernos, sino de algo más lundamenlal y que tiene que ver con los cimientos mismos de la civilización capitalista. Es esta civilización en cuanto depredadora del medio ambienle, manipuladora del otro y consumisla - la que se ve cuestionada por la TC.

\subsubsection{La critica al clentificlsmo positivista en la TC}

Deciamos que la racionalidad instrumental (o estratégica) se ha expandido a la totalidad de las relaciones sociales. Esla expansión se ha visto legitimada por el presunto carácter de saber absoluto y perfecto que ha asignado la modernidad al saber cientíllco-natural, nacido para orientar las prácticas de dominación y control de la naluraleza. Pues bien, junto a la expansión de la racionalidad instrumenlal, las ciencias naturales se han ido convirtiendo en el modelo y paradigma de lo que es conocimiento verdadero (cientílico). Este proceso de cientifización del saber ha reforzado la consciencia de que las pretensiones manipuladoras y dominadoras son legítimas porque son científicas (verdaderas).

El orden tecnoeconómico se sostiene vla los avances tecnológicos posibilitados por las ciencias naturales. Este orden está regido por una lógica de control, cálculo y manipulación sostenida por el saber cientificonalural. Al expandirse esa lógica al conjunto de la sociedad, también se expande en forma colonizadora el paradigma de las ciencias naturales hacia los otros saberes. Es asi como se cierra el círculo funcional de la modernidad capilalisla: una praxis manipuladora tiene que ser legitimada por un saber manipulador.

Ese clrculo tiene que ser cuestionado. Tiene que ser cuestionada la pretensión de hacer de las ciencias naturales el modelo y paradigma de todo saber. Hay que enfrenlarse críticamente a aquella corriente de pesamiento que es portavoz de esa pretensión: el positivismo lógico. Mediante esta crítica se trata de relrotraer la lógica del control y la dominación - asi como al conocimienlo que la sustenta - hacia sus ámbitos especificos de funcionamienlo. Asimismo, se trata de "liberar" a lo político y cultural de una lógica (manipuladora) que les ha sido impuesta y de abrir cauces a unos conocimientos "liberados" de sesgos positivislas y cientificistas.

El punto de apoyo de esta propuesla en la TC es la critica filosófica del lenguaje en el positivismo lógico. Con esta crílica nos las habemos con uno de los aportes más imporlantes de la TC a la lilosofía moderna. 


\subsubsection{El lenguaje en el positlvismo Ióglco}

Para el positivismo lógico (PL) entre lenguaje y realidad existe una correspondencia cuasi perfecta. El lenguaje viene a ser algo asi como un "rellejo" de la realidad. En las versiones más radicales del PL $\rightarrow$ por ejemplo, en el "atomismo lógico-, el mundo que rodea al individuo está compuesto por unos elementos últimos, es decir, por unos "átomos" articulados de una forma determinada. Son estos "hechos atómicos" to más genunino de la realidad. El lenguaje es un "instrumento" que permile al hombre "describir" esos hechos alómicos. No se trata, sin embargo, de cualquier lenguaje. Tiene que ser forzosamente un lenguaje lógico-matemático.

Sólo el lenguaje lógico-malemálico se corresponde perfectamente -nos dicen los autores de esla corriente (Russell, Peano, "primer Willgenstein", Carnap,...) - con los hechos experimenlados sensiblemente. "En un lenguaje lógicamente perfeclo las palabras de una proposición se corresponderian una a una con los componentes del hecho correspondiente" (B. Russell) ${ }^{67}$. El significado de una proposición deriva, en consecuencia, de su correspondencia con los hechos alómicos: "si los únicos hechos genuinos son los hechos atómicos, entonces loda oración significaliva debe ser analizable en liguras de hechos alómicos" (J. R. Urson). EI PL en su versión "alomista"- siempre se remilirá a los hechos atómicos (experienciables y verificables) para legitimimar la validez o invalidez científica de las proposiciones y enunciados verbales. Este es el "criterio de verificación" - de tipo "reductivo empirisla"- al que se remiten, en úllima instancia, estos autores.

Pero hay un segundo "criterio de verificación" no menos imporlante y que, en cierto modo, es el que caracteriza al PL propiamente dichose. Este criterio se centra en la estruclura misma de los enunciados y proposiciones verbales. Parte de dos supuestos fundamentales: a) que el lenguaje humano posee, en el londo, un estructura lógica; y b) que el lenguaje lógico-matemático -por su rigor y exactilud- es un lenguaje perfecto. Es por su perfección que el lenguaje lógico-malemático es capaz de de corresponderse término a término con los datos de la realidad sensible.

De esta forma, el PL se interesará melodológicamente por delerminar la eslruclura lógica de las proposiciones "complejas", a través del análisis lógico-matemático de sus partes componentes. Es decir, tratará de validar o invalidar el sentido (cienlílico) de una proposición mediante el análisis lógico-formal de sus estrucluras. Por to mismo, no se busca delerminar si lo analizado expresa o no hechos empiricos. Lo que imporla es verilicar si los componentes elementales del enunciado en cuestión 
eslán entrelazados entre si de lorma lógicamente consislente. El PL realiza un "análisis lógico del lenguaje" como procedimienlo de verilicación ${ }^{69}$. Al verificarse posilivamente la consistencia lógica del enunciado analizado, será claro que estamos ante un enunciado con significado, es decir, con valor científico. En caso contrario, estaremos ante una formulación verbal carente de sentido, que no ha respelado las reglas lógicas constitulivas del lenguaje.

El PL reivindica dos dimensiones fundamentales del lenguaje: la dimensión sintáctica y la dimensión semántica. Por tanto, se apoyará en un sistema de simbolos (lógico-matemálicos) regulados por reglas de combinación permitidas y no permitidas. Estas reglas (axiomáticas, de inferencia, etc.), en cuanto mero cálculo lógico, serán reglas sintácticas, es decir, reglas ajenas a la interpretación. Esle procedimienlo es propio de los sistemas logísticos ${ }^{70}$. Pero a las tórmulas del sistema logistico se les puede asignar un significado. Este significado estará regulado por reglas semánticas. El lenguaje que reune estas dos dimensiones es un lenguaje formalizado. Así, el leguaje formalizado por excelencia será, en la perspectiva del $\mathrm{PL}$, el lenguaje lógico-malemático. Sus Iórmulas de combinación serán estrictamente reguladas por una sinlaxis rigurosa y se les asignará un sentido a partir de unas reglas semánticas determinadas. Estas reglas -y la simbología en la que se expresan- se aplicarán en el análisis lógico de los enunciados complejos y, a partir de alli, se establecerá su consistencia o inconsislencia lógica-formal.

Esla concepción del lenguaje del PL posee virtualidades inobjelables. En efecto, los grandes avances en la informática y la computación son en buena medida tribularios del impulso que los PL dieron a las investigaciones lógico-malemáticas. Sin embargo, es una concepción que posee limilaciones graves en lo que se refiere a la concepción de hombre y en lo que se reliere a su concepción del lenguaje. Su supuesto es que el hombre es un individuo solitario que se vale del "instrumento"-lenguaje para "designar" los estados de la realidad que le rodea. Es decir, el PL maneja una concepción solipsista del hombre. Esle solipsisimo será fuertemenle criticado por la filosofía del lenguaje posterior, especialmente por la teoría del lenguaje de la TC. Asimismo, al centrarse en las dimensiones sinlácticas y semánticas del lenguaje olvida una dimensión constitutiva de ésle: su dimensión pragmática.

\subsubsection{La superaclón criflca del PL: la teorla de los "juegos del lenguaje" y la teoría del "consenso Intersubjetivo"}

Para el PL el sujelo humano es el "autor y juez final de sus intencio- 
nes de significado"71. El "segundo Wittgenstein"72 pone en cuestión esta perspectiva del PL, que "entiende el significado según el modelo del nombre" (A. Wellmer). Si queremos conocer el significado de las palabras o de un determinado sistema lingūíslico - nos dice Wittgensteinno debemos remitirnos al sujelo, sino que debemos atender $-y$ ser partícipes- del "juego de lenguaje" correspondiente; es decir, tenemos que remitirnos a la "práclica inlersubjeliva" que realiza la comunidad de hablantes-oyentes en cuyo contexto las palabras adquieren su significado específico.

"Los juegos del lenguaje no son juegos, sino formas de vida. Son conjunlos de actividades lingüisticas y no lingūísticas, instituciones, prácticas y significados encarnados en ellas"73. Estos "juegos del lenguaje" tienen sus reglas específicas, cuya vigencia "no se funda en otra cosa sino en la práctica de su propia aplicación a una clase de casos abierta en principio, de forma que la relación de significanle es una encarnación de esta práctica y no una relación entre dos relata en cierto modo ya dados con independencia el uno del otron74.

En la óplica de Wittgenstein, el sujeto solitario -presupueslo por el PL- pierde su predominancia y cenlralidad. Antes que el sujelo y su individualidad solipsisla eslá la comunidad intersubjetiva que se halla inserta -y participa - en "juegos de lenguaje" determinados. Los significados lingüísticos son resultado de la "forma de vida" propia de la comunidad; es decir, lo significados son resultado de la praxis intersubjetiva de los individuos. Cada comunidad, en consecuencia, participará de unos "juegos de lenguaje" propios y relativos a su específica "forma de vida". Al margen de esa comunidad,. no habrá forma de entender los usos lingūisticos que la caracterizan ni su significado. Sólo participando de las prácticas comunicativas de la comunidad $-y$ de su correspondiente "forma de vida"- comprenderemos tanto los usos lingüísticos de la misma como el signilicado de éslos.

Ya en Wittgenslein va quedando claro que el significado de los signos lingūisticos depende de la comunidad de comunicación en la que los mismos son utilizados. Los desarrollos posteriores de la filosolía del lenguaje $\rightarrow$ sobre todo, en los trabajos de Otto Apel y Habermas ${ }^{75}$ - han radicalizado esla lesis de Wittgenstein. Para estos autores, no se trata sólo de que el significado de las palabras dependa de unos "juegos de lenguaje" determinados, sino que la verdad que se atribuye a los signos lingülsticos (palabras y conceplos) es una verdad consensual, es decir, una verdad que es resullado de un acuerdo inlersubjetivo eslablecido entre los miembros de la comunidad de comunicación. "La cuestión básica de la teoría del significado, a saber: qué quiere decir entender el 
significado de una expresión lingūistica, no puede aislarse de la pregumla de en qué contexto esa expresión puede ser aceptada como válida"7e.

"El semido en el cual un enunciado puede ser verdadero o falso no se basa en las condiciones de objetividad experimentales, sino en la posibilidad de fundamentación argumentativa de una petensión de validez criticable" $"$.

No hay, en esie senlido, "verdades objetivas" (verdades releridas a hechos cientificamente verificables) al margen de la comunidad de hablamtes-oyemles que, consensualmente (argumentativamente), acepla una determinada proposición como una proposición cientílica. El lenguaje lógico-matemático es una consirucción conceplual cuyo ámbito de verdad ha sido establecido por una comunidad de comunicación determinada: la comunidad de científicos. Las verdades que transmile son verdades establecidas intersubjetivamente $-y$ consensualmente- por dicha comunidad, que está orientada por unos intereses particulares y concrelos.

"La verdad es que no son las proposiciones básicas rellejos de los hechos en sl; más bien traen a expresión éxitos o fracasos de nuestras operaciones.. Los hechos de experiencias cientílicas relevantes se constituyen como lales merced a una organización previa de nuestra experiencia en el círculo de funciones de la acción instrumental"78.

Desde esta perspectiva, las tesis del PL sobre el presunto carácter absoluto y perfecto del lenguaje lógico-matemálico se vienen abajo. La lógica y la malemálica dejan de ser el modelo de los demás lenguajes, en virtud del cual éstos serian invalidados o validados como signilicativos (=científicos) o no signilicativos (=no científicos). Incluso algunos, como el "segundo Wittgenslein", Ilegan a pensar que el lenguaje más rico es el lenguaje cotidiano, a la par del cual el lenguaje lógico-matemático es un artiticio desvinculado de la vida real de los hombres.

La TC reivindica la dimensión antropológica fundamental de la "comunidad de comunicación" (Habermas) o de "argumentación" (Otlo Apel). Esta comunidad, en cuanto que interactúa intersubjetivamente a través de la "acción comunicativa", constiluye el a priori transcendental de cualquier proyecto y praxis histórica y social. Ese a priori comunicativo está constituido por "actitudes que necesitan de la evaluación crítica mediante argumentos porque no pueden ser deducidas lógicamente ni probadas empíricamente... Se manifiestan como acertadas o equivocadas. Pues se miden por la necesidad melalógica de intereses, que nosotros no podemos tijar ni representar, sino con los que nos lenemos que encontrar"70. 
Todo saber está cimentado en unos supuestos metalógicos, que es no más que los intereses de la comunidad de comunicación en la que se elabora ese saber. "En el ejercicio de las ciencias empirico-analíticas interviene un interés técnico del conocimiento; en el ejercicio de las ciencias histórico-hermenéuticas interviene un interés práctico del conocimiento, y en el ejercicio de las ciencias orientadas hacia la critica interviene aquel inlerés emancipatorio del conocimiento ${ }^{\text {nso }}$. Haber olvidado esa vinculación entre conocimiento $\theta$ interés, así como la vinculación realizada entre ambos por la comunidad de comunicación mediante la acción comunicativa: he aqui el error garralal del positivismo lógico.

\section{A modo de conclusión}

Hemos hecho una revisión de las principales corrientes socio-culturales que intervienen en el llamado "debate post-modemo": los NC, los postmodernos y la TC. A través del diagnóstico que dichas corrientes hacen de la modernidad y de las terapias que proponen para entrentarla, nos hemos acercado a los problemas fundamentales de nuestro tiempo. Es indudable que esos movimientos socio-culturales constituyen un relo para América Latina, tanto en lo que dicen como en lo que ocultan. Superar el aislamienlo cullural exige conlronlarse con quienes van imponiendo el ritmo en la discusión, no para asimilar acrílicamente sus tesis, sino para enriquecer críticamenle la propia cultura y para poder aportar algo desde la propia realidad.

¿Cómo responder desde América Latina al NC, al post-modernismo y a la TC? ¿Cuáles son los principales desalíos que presentan esos movimienlos socio-culturales? ¿Cómo enfrentarlos desde un horizonte liberador? Intentaremos reflexionar someramente sobre estas cuestiones, examinando cada una de las corrientes analizadas a la luz de esas interrogantes.

a) Los Neoconservadores. Los NC tienen una propuesta socio-cultural bien definida, que consiste en la recuperación de la tradición religiosa judeo-cristiana, con miras a la legilimación del capilalismo norleamericano. Son conscientes de la expansión del sistema y quieren dotarlo de unos valores que lo legitimen como el mejor orden posible. Su afinidad con el judeo-crislianismo - piensan los NC- es la mejor prueba de su superioridad sobre cualquier otro modelo allernativo.

Lo propio de la propuesta NC es su manipulación de las tradiciones bíblicas, que son puestas al servicio de un sistema que se sustenta en una lógica contraria a la lógica del Dios de Israel, es decir, una lógica que produce la muerte de la mayor parte de la humanidad. Esta preten- 
sión NC constituye uno de los desafíos más importantes para los proyectos de liberación que se dibujan en América Latina. En concreto, es uno de los desafios más serios que tiene ante si la teología de la liberación (TdL). Es desde la TdL que América Latina puede enirentar crílicamente las prelensiones manipuladoras de la religión presentes en el NC. En to fundamental, la TdL tiene que seguir defendiendo que el Dios judeocrisliano es un Dios de la vida y no un Dios de la muerte. Un Dios cuya gloria mayor es que el pobre viva (Mons. Romero).

b) Los Post-modernos. Esta corrienle socio-cultural ha lenido un gran auge en las últimas décadas, sobre todo en los circulos intelectuales europeos. Su presencia en América Latina es todavía muy reducida ${ }^{\text {B1 }}$. Sin embargo, plantea una serie de cuestiones que pueden volverse muy alractivas para una cultura muy abierta y receptiva hacia las novedades, aunque no siempre se haga presente en esa recepción el espiritu crílico y creador.

Hay indudables virtudes en la propuesta post-moderna, que pueden ser provechosas para la cultura lalinoamericana. Sobre lodo, pueden dotarla de ese espírilu crílico — propio de la posimodernidad- que no se deliene ante ninguna autoridad y que acepta la vigencia de un pluralismo de visiones de mundo que se legitiman en la discusión y el diálogo. Esto habrá de ser muy saludable en un contexto marcado históricamente por loda clase de autoritarismos de tipo religioso, político y/o ideológico.

Pero también hay que estar atentos a los peligros que se derivan de una propuesta radicalmente anti-ilustrada como la sostenida por los post-modernos. En América Latina es sumamenle peligroso condenar las propuestas emancipadoras, bajo el argumento de que siempre conducen -una vez que se concretizan- a nuevas formas de opresión. En América Latina alerrarse a un planleamiento de esa naluraleza significa sancionar una siluación histórica en la que las grandes mayorias apenas pueden garantizarse ese "minimo de los minimo" (L. Boll) que es su propia vida. Quizás hablar de emancipación y liberación en América Latina les suene a muchos como algo puramente utópico $-y$ a lo mejor tendrán algo de razón-, pero sin esa utopía nueslros pueblos están condenados a la muerte y a la opresión sin resistencia posible. Pese a cualquier postmodernismo cultural, América Latina urge de proyeclos liberadores (emancipadores), porque sus pueblos viven en una siluación de lerrible inhumanidad.

c) La Teoría Crítica. Esta corriente es la que está llamada a incertarse en la dinámica cultural latinoamericana de una forma positiva, en vislas a la creación de una cultura de la liberación. El que no reniegue de la ilustración y que se inspire en ella para elaborar un proyecto 
emancipador a la altura de las necesidades de la humanidad actual la hace particularmente relevanle para la siluación latinoamericana.

La propuesta efectuada por esta corriente para fundamentar la unidad diabógica de la comunidad, como condición de posibilidad de una praxis humana emancipadora, hace ver que las aspiraciones de liberación de los pueblos latinoamericanos no son mera utopla $\theta$ ilusión. Desde una perspectiva teórica - nos dice la TC- es legítimo aferrarse todavía a relalos emancipadores.

Ciertamente que en América Latina el problema de la emancipación no es algo primariamente teórico, sino una exigencia que se les impone a las mayorias populares desde su misma miseria y opresión reales. Sin embargo, esa exigencia -y la praxis que desencadena- necesita la luz de un discurso teórico que la oriente y sea capaz de soslenerla racionalmente. Pensamos que la TC - ahora que los marxismos ortodoxos han perdido legitimidad como momento leórico de una praxis revolucionaria auléntica- puede dar un aporte esencial a la elaboración de un discurso teórico que esté en lunción de la emancipación de las mayorias oprimidas de América Latina y, en general, del Tercer Mundo.

\section{NOTAS BIBLIOGRAFICAS}

1. Hinkelammert, F., "El papel regulador del Estado y los problemas de la auloregulación del mercado". Pasos, No. 33, p. 10.

2. Ib. p. 11

3. Crr. Las interesantes rellexiones de Noam Chomski sobre las repercusiones -económicas, pollticas y militares - de la "derechización" occidental encabezada por EEUU en el Tercer Mundo, especialmente en América Central. Chomski, N., "La lucha por la democracia en un mundo en cambio". ECA, XLVI(512):559-574

4. Mardones, J. M., "Neoconservadurismo y moral: el abuso de la ética por el sistema". Sal Terrae. Revista hispanoamericana de teologia pastoral. Julioagosto de 1990, p. 515

5. lb. p. $\mathbf{5 1 8}$

6. Clr. Mardones, J. M., Capitalismo y religión. La religión politica neoconservadora. Santander, Sal Terrae, 1991; Mardones, J. M., "La kufturkampf del neconservadurismo norteamericano. La recreación del consenso social desde la relectura de la tradición liberal". Realidad EconómicoSocial. III(16):413-444

7. Cir. Mardones, J. M., Postmodernidad y cristianismo. El desafio del fragmento. Santander, Sal terrae, 1988

8. Mardones, J. M., Capitalismo y religión... p. 66

9. Mardones, J. M., "Hacia un cristianismo universal y policéntrico". En Postmodernidad y neoconservadurismo. Navarra, Verbo Divino, 1991. p. 241 
10. Nota 4, pp. 516-517

11. Nola 8, pp. 54-56

12. Ib. pp. $40-41$

13. Ib. p. 153

14. Nola 4, p. 519

15. Para tener un visión de conjunto de la evolución del movimiento post-moderno, Cir. Huyssen, A., "Guía del postmodernismo". En Berman, M., et. al., El debate modernidad-postmodernidad. Buenos Aires, Puntosur, 1989. pp. 266318

16. Clr. Mardones, J. M., -Modernidad y post-modernidad. Un debate sobre la sociedad actual". Razón y Fe. Septiembre-oclubre, 1986. pp. 214 y ss.; González, L. A., "Modernidad y postmodernidad". Taller de Letras. IX(137):23-40

17. Hassan, I., "The crilic as innovator: the tulzing statement in $\times$ Irames". Citado por Welmer, A., "La dialéctica de modernidad y posmodernidad". En Ob. Cit, nola $15, p .321$

18. Lyolard, J. F., Apathie in der theorie. Citado por Wellmer, A., nola 17, p. 323

19. Wellmer, A., nota 17, p. 324

20. Lyotard, J. F., La condición postmoderna. Citado por Lash, S., "Postmodernidad y deseo". En Ob. Cit., nota 15, p. 373

21. Wellmer, A., nota 17, p. 325

22. Braudillard, J., Tod der moderne. Eine diskussion, konkurbuch. Citado por Welmer, A., nola 27, p. 324

23. Wellmer, A., nota 17, p. 324

24. Ib. p. 333

25. Ib.

26. $\mathrm{lb}$.

27. Ib.

28. Ib. p. 340

29. Ib.

30. Ib. p. 341

31. Ib. p. 342

32. $\mathrm{lb}$.

33. Ib. p. 335

34. Ib.

35. Ib.

36. Ib. p. 336

37. lb. pp. $346-347$

38. Ib. p. 347

39. Mardones, J. M., Postmodernidad y cristianismo. Santander, Sal Terrae, 1988. p. 48

40. Ib.

41. Ib. pp. $60-61$

42. Ib. p. 60

43. Ib.

44. Ib.

45. Ib. pp. 60-61 
46. Ib.

47. Ib.

48. Ib. p. 61

49. lb.

50. lb.

51. Clr. Bukc-Morss, S., Origen de la diálectica negativa. Theodor W. Adorno, Walter Benjamin y el instituto de Frankfurt. México, siglo XXI, 1981

52. Mardones, J. M., Postmodernidad y... p. 53

53. J. Habermas desarrolla sus tesis lundamentales en su obra Teoria de la acción comunicativa. Madrid, Taurus, 1988. $2 \mathrm{~V}$.; K. O. Apel to hace en La transformación de la filosofia. Madrid, Taurus, 1985. $2 \mathrm{~V}$.

54. Ib. p. 52

55. McCarthy, Th., "Pellexiones sobre la racionalización en la Teoria de la acción comunicativa". En Guiddens, A., et. al. Habermas y la modernidad. Madrid, Cátedra, 1988. p. 278

56. Berstein, R. J., "Introducción" a Ob. Cit., nota 55, p. 21

57. Cfr. Habermas, J., Conocimiento e interés. Madrid, Taurus, 1983; González, A., Introducción a la práctica de la filosofia. San Salvador, UCA/ Ed., 1989. pp. 24-36

58. Berstein, R. J., lb. pp. $46-47$

59. lb. p. $4 \theta$

60. Berstein, R. J., Ib. p. p. 49

61. Mardones, J. M., "Para un diagnóstico socio-cultural de nuestro tiempo". En Ob. Cit. nota 9, p. 20

62. Mardones, J. M., "La sociedad de consumo y el tipo de hombre que produce". En Ob Cit. nota 9, p. 192

63. lb. p. 194

64. Ib. p. 196

65. Ib. p. 197

66. lb. p. 202

67. Una presentación de los supueslos y lesis básicas del positivismo lógico se encuenlra en Weinberg, J. R., Examen del positivismo lógico, Madrid, Aguilar, 1959

68. Cfr. Ayer, A., Lenguaje, verdad y lógica, Barcelona, Martinez Roca, 1971

69. Ibid. p. 144.

70. Abbagnano, N., Diccionario de filosofia. México, FCE, 1987. p. 1083.

71. Wellmer, A., nota 17, p. 340.

72. Cuando los especialislas hablan del "primer Witgenslein" se refieren al Wittgenstein del Tractactus logico-philosophicus. Cuando hablan del "segundo Wittgenstein" se relieren al Wittgenstein de las Investigaciones filosóficas (Philosophical investigations, 1953) y del Cuaderno azul y marrón (The blue and brown books, 1958). .

73. lb., nota 28

74. Ib. p. 341.

75. Cfr. Nota 53; Mardones, J. M., Razón comunicativa y teorla critica: fundamentos normativos de la teoria de la sociedad. Bilbao, Universidad del País Vasco, 1986 
76. Habermas, J., "Acciones, actos de habla, interacciones lingüísticamente mediadas y mundo de la vida". En Pensamiento postmetafísico. Madrid, Taurus, 1990. p. 79

77. Habermas, J., nola 56, p. 310

78. Habermas, J., "Conocimiento e interés". En Cciencia y Técnica como Ideologla, Madrid, Tecnas, 1989, pp. 159-181.

79. Ib. p. 174

80. Ib. p. 169

81. Aunque ya hay algún eco de ello en algunos trabajos de aulores lalinoamericanos. Ctr. Lechner, N., "La democratización en el conlexto de una cultura post-moderna". En Cultura política y democratización. Santiago de Chile, CLACSO/FLACSO/ICI, 1987; Bruner, J. J., "Notas sobre la modernidad y lo postmoderno en la cultura latinoamericana". David y Goliath, Revista de CLACSO, XVII(52): $31 \mathrm{ss;}$ Erbsen de Maldonado, K., "Tendencias del desarrollo político en América Latina en la post-modernidad. Un enloque desde Centro América". Panorama Centroamericano, No. 20, oclubre-diciembre, 1990. pp. 15-22 